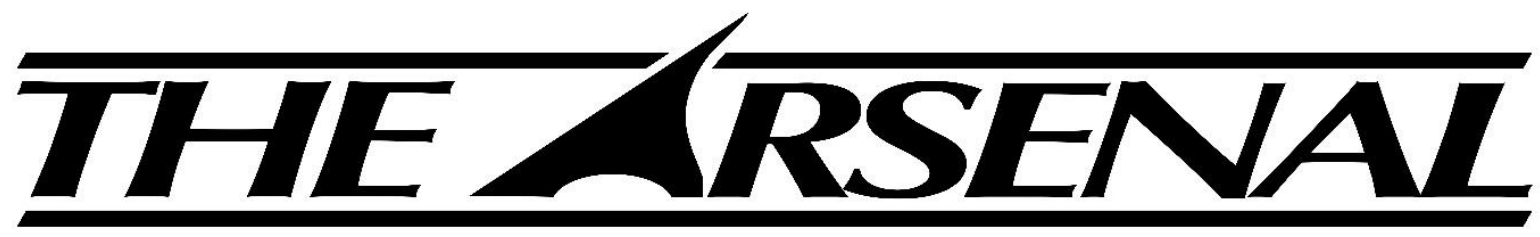

Augusta University's Undergraduate Research Journal

ISSN 2380-5064 | The Arsenal is published by the Augusta University Libraries | http://guides.augusta.edu/arsenal

Volume 4, Issue 1 (2021)

Special Edition Issue

ENDOTHELIAL MINERALOCORTICOID RECEPTOR DELETION ABLATES LEPTIN-INDUCED PREECLAMPSIA CHARACTERISTICS IN PREGNANCY

Derrian Wright, Simone Kennard, Galina Antonova, Iris Z Jaffe, Eric J Belin de Chantemele, and Jessica L Faulkner

\title{
Citation
}

Wright, D., Kennard, S., Antonava, G., Jaffe, I. Z., Belin de Chantemele, E. J., \& Faulkner, J. L. (2021). Endothelial mineralocorticoid receptor deletion ablates leptin-induced preeclampsia characteristics in pregnancy. The Arsenal: The Undergraduate Research Journal of Augusta University, 4(1), 42. http://doi.org/10.21633/issn.2380.5064/s.2021.04.01.42 


\section{Endothelial Mineralocorticoid Receptor Deletion Ablates Leptin-Induced Preeclampsia Characteristics in Pregnancy}

Presenter(s): Derrian Wright

Author(s): Derrian Wright ${ }^{1}$, Simone Kennard ${ }^{1}$, Galina Antonova ${ }^{1}$, Iris Z Jaffe ${ }^{2}$, Eric J Belin de Chantemele ${ }^{1}$, and Jessica L Faulkner ${ }^{1}$

Faculty Sponsor(s): Eric J Belin de Chantemele, $\mathrm{PhD}$

Affiliation(s): ${ }^{1}$ Vascular Biology Center, ${ }^{2}$ Molecular Cardiology Research Institute (Tufts Univ.)

Funding: NIH and AHA

\section{ABSTRACT}

Obesity increases the risk for preeclampsia (PE), a hypertensive syndrome of pregnancy. Obese PE patients demonstrate increases in plasma leptin levels in midgestation. We have shown that pregnancy increases endothelial mineralocorticoid receptor (ECMR) expression and that ECMR mediates leptin-induced endothelial dysfunction and hypertension in non-pregnant females. We, therefore, hypothesized that ECMR deletion (ECMR-/-) protects from the development endothelial dysfunction, hypertension and fetal growth restriction in leptin-infused pregnant mice. Pregnant ECMR+/+ and ECMR-/mice were infused with leptin by osmotic minipump from gestation day (GD)11-18 and thoracic aortas assessed for vascular function by wire myography or implanted with radiotelemeters for systolic blood pressure (BP) measurement. Leptin decreased pup weight and placental efficiency indicating fetal growth restriction, which was restored in ECMR-/- mice infused with leptin. Leptin infusion increased BP and ablated circadian rhythm in ECMR+/+, but not ECMR-/- pregnant mice. ECMR deletion protected pregnant mice from leptin-induced impairment in acetylcholine (endothelial-dependent dilator) and phenylephrine ( $\alpha$ 1receptor-mediated constriction) in aortas. Relaxation to acetylcholine with nitric oxide (NO) synthase inhibitor (LNAME) showed restoration of endothelial function in ECMR-/-+leptin mice was NO-dependent. These data indicate that ECMR deletion improves BP, vascular function and fetal growth in an obesity-associated, leptininfusion model of PE.

Received: 02/15/2021 Accepted: 03/30/2021

Correspondence: Derrian Wright, Augusta University, $112015^{\text {th }}$ St. Augusta, GA 30912, derwright@augusta.edu 42

The Arsenal 